\title{
The Rochester OSA Optics Suitcase: 13 years of middle school outreach
}

\section{Cristina Canavesi, Theresa Donlon, Stephen Jacobs}

Cristina Canavesi, Theresa M Donlon, Stephen D Jacobs, "The Rochester OSA Optics Suitcase: 13 years of middle school outreach," Proc. SPIE 8481, Optics Education and Outreach II, 84810M (15 October 2012); doi: $10.1117 / 12.927633$

SPIE Event: SPIE Optical Engineering + Applications, 2012, San Diego, California, United States 


\title{
The Rochester OSA Optics Suitcase: 13 years of middle school outreach
}

\author{
Cristina Canavesi $^{\mathrm{a}, \mathrm{b}}$, Theresa M. Donlon ${ }^{\mathrm{a}, \mathrm{c}}$, and Stephen D. Jacobs ${ }^{{ }_{\mathrm{a}, \mathrm{c}}}$ \\ ${ }^{a}$ Optical Society of America, Rochester Section, Inc., Rochester, NY, USA \\ ${ }^{\mathrm{b}}$ The Institute of Optics, University of Rochester, Rochester, NY 14627, USA \\ ${ }^{c}$ Laboratory for Laser Energetics, University of Rochester, Rochester, NY 14623, USA
}

\begin{abstract}
The Rochester Section of the Optical Society of America (ROSA) developed a youth outreach program in 1999 to be presented in middle schools by scientists, engineers and engineering students. The objective was to kindle interest in technology careers, especially those related to optics, photonics, and optical engineering. Three in-class experiments using individual take-home theme packets that explore color in white light were devised early in the program, and these have proven to be the key to its success. Over the past 13 years, with financial support from a variety of organizations and individuals, ROSA has manufactured and delivered over 450 Optics Suitcases to groups in 34 US states and 54 countries. The presentation guide is now available in 4 languages besides English. In this paper, the elements of an Optics Suitcase presentation are reviewed, and examples of outreach events are used to document its success.
\end{abstract}

Keywords: Outreach, education, optical demonstrations

\section{INTRODUCTION}

The Rochester section of the Optical Society of America (ROSA) was founded in 1915. Its almost 100 years of history are filled with many accomplishments. One of its greatest successes is the outreach program called Optics Suitcase, which was started in 1999 under the guidance of ROSA President Don Golini. In the past thirteen years, the Optics Suitcase effort has grown to have an international presence, with over 450 Suitcases distributed in 34 US states and 54 countries to date. In this paper, we give an overview of the history of the Optics Suitcase, detail its contents, and present examples of outreach events.

\section{THE OPTICS SUITCASE}

The Optics Suitcase program was initiated in 1999 by the ROSA Education Committee led by Stephen Jacobs, at the request of President Donald Golini to become more involved with youth outreach in the community. The idea of a 40 minute in-school presentation to children ages 9-13 that could be given by our members was developed, and initial funding was provided by ROSA to purchase a set of supplies to create a portable Suitcase. Three demo experiments exploring color in white light through diffraction, polarization and selective reflection from liquid crystals were assembled into take-home theme packets, with the intention of giving these out to the students.

The Optics Suitcase program helps promote optical careers to children in school by exposing them to examples of what can be achieved with optical engineering. Key elements of the success of the Optics Suitcase include interesting demonstrations, interactive participation, and take-home packets. Children often repeat at home the lessons learned, showing the take-home demonstrations to friends and family members.

\subsection{Contents of the Optics Suitcase}

With slight variations throughout the years, the contents of the Optics Suitcase are for the most part the same as in the original version of the suitcase ${ }^{1}$. The Optics Suitcase comes in a sturdy case that facilitates transportation and contains all the material needed for the presentation, as can be seen in Fig. 1. Both reusable supplies and take-home theme packets are included. A typical in-class presentation takes about 40 minutes. The take-home supplies include 75 copies

*http://osarochester.org sjac@1le.rochester.edu; phone: +1 (585) 275-4837

Optics Education and Outreach II, edited by G. Groot Gregory, Proc. of SPIE Vol. 8481

84810M · C 2012 SPIE · CCC code: 0277-786/12/\$18 · doi: 10.1117/12.927633 
of the periodic table of the elements and 225 theme packets that explore color in white light through three hands-on experiments ( 75 copies of each set).
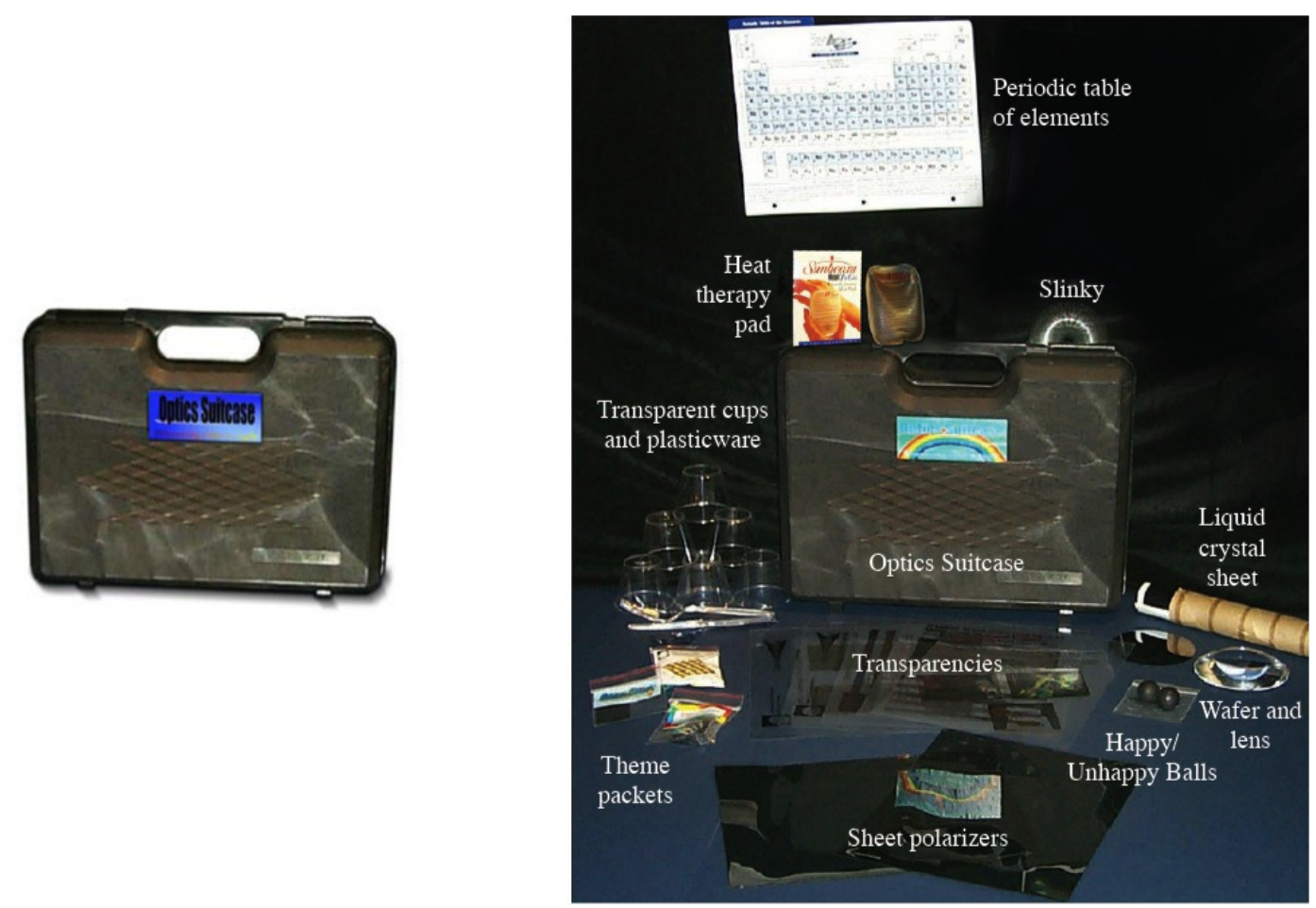

Figure 1. The Optics Suitcase.

A typical Optics Suitcase presentation starts off by using some of the reusable supplies included in the Suitcase, shown in Fig. 2. These activities are used to break the ice and encourage children to be curious about science.

Heat pack

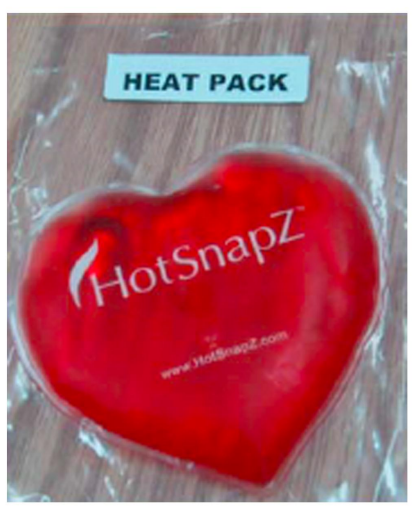

a)
Happy/unhappy balls

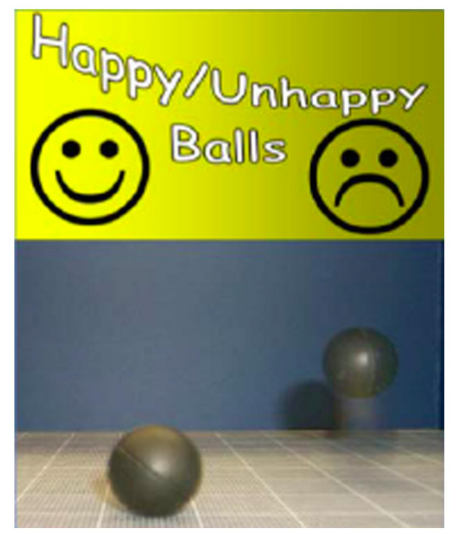

b)

Figure 2. The heat pad and happy/unhappy ball demonstrations serve as ice-breakers during the presentation. 
A heat therapy pad is used to show how chemistry can be used to improve our lives. The happy/unhappy balls are use to illustrate how materials science allows us to control the properties of materials. The rubber balls appear the same, but when they are dropped, it becomes clear to the children that they are not the same. In fact, since only one ball is vulcanized, when the balls are dropped, one bounces while the other does not. The children are taught that technology can transform materials to make them serve different applications.

To introduce the topic of optical engineering, a wafer of silicon and a silica lens are shown (see Fig. 3). With the aid of a periodic table, the children learn that, with the addition of oxygen, silicon turns transparent at visible wavelengths. The presenter can talk about transparency and reflection, and discuss examples of the use of silicon wafers and lenses in everyday applications.

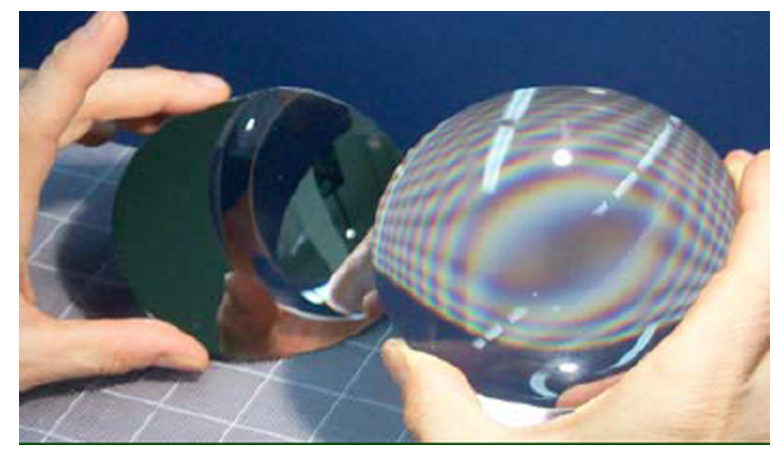

Figure 3. Silicon wafer and silica lens. The addition of oxygen turns silicon from opaque to transparent at visible wavelengths.

The first optical demonstration - and possibly the most popular among children - is on diffraction. The "Rainbow Peephole" take-home packet, which includes a flashlight, a diffraction peephole and an information sheet, is shown in Fig. 4(a).

Rainbow Peephole

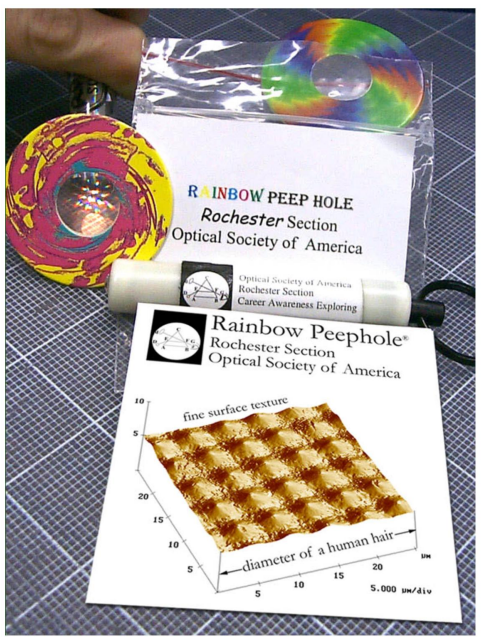

a)
Magic Stripes

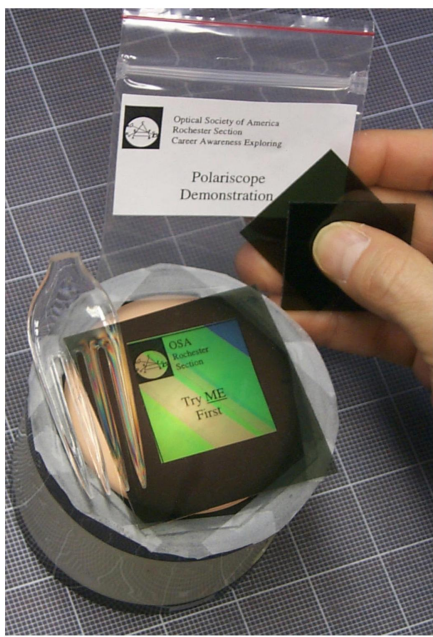

b)
Magic Patch

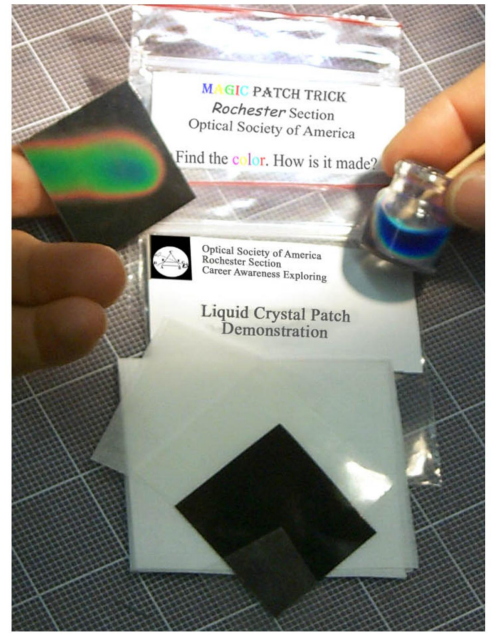

c)

Figure 4. The three main demonstrations contained in the Optics Suitcase, featuring the take-home packets on (a) diffraction, (b) polarization, and (c) selective reflection. 
By holding the diffraction peephole up to their eye and looking at various light sources, including the flashlight provided with the packet, children learn about diffraction gratings, and how they can be used to split the spectrum of white light into its colored components. A micrograph of the fine structure of the grating is included in the packet. This demonstration can start a discussion on the optical spectrum, visible wavelengths and white light.

The second take-home packet, featuring polarization, is called "Magic Stripes", as shown in Fig. 4(b). It consists of two polarizers and a small collection of various plastic utensils. Using the two linear polarizers provided, children can create a polariscope to visualize the stress in plastic pieces. Two large sheet polarizers are also included in the Suitcase as an aid for the demonstration. A Slinky, included in the Suitcase, can be used to illustrate the properties of waves.

The third take-home packet, consisting of a liquid crystal patch as shown in Fig. 4(c), is called "Magic Patch". It introduces the topic of selective reflection. The presenter can press the face or a hand on the large sheet of sheet of liquid crystals included in the Suitcase to illustrate how liquid crystals react to temperature. The sheet reflects different colors depending on the temperature.

Additional modules for in-depth lectures are also available. In the liquid crystal module, the children can assemble a mood patch by creating a sandwich of liquid crystal materials between two pieces of plastic, as shown in Fig. 5. The liquid crystals are placed on a piece on black plastic (Fig. 5(a)), covered with a piece of clear plastic (Fig. 5(b)), and sealed with transparent tape (Fig. 5(c)) to create a mood patch. A video of this demonstration was made by the OSA student chapter of École Polytechnique de Montréal and is available on the internet ${ }^{2}$.

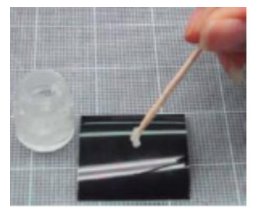

a)

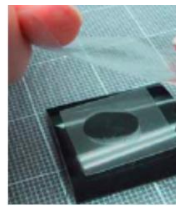

b)

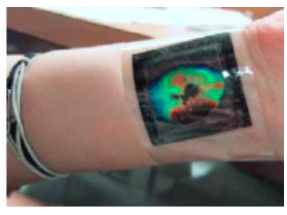

c)

Figure 5. Mood patch assembly.

\subsection{Educational merits of the Optics Suitcase}

In 2010, through a partnership between OSA Foundation and the Greater Milwaukee Foundation, the Optics Suitcase was presented 25 times to over 575 students in grades 5-8 in Milwaukee, WI. For the first time, a quantitative measure of the impact of the program was obtained, as shown in Figs. 6 and 7.

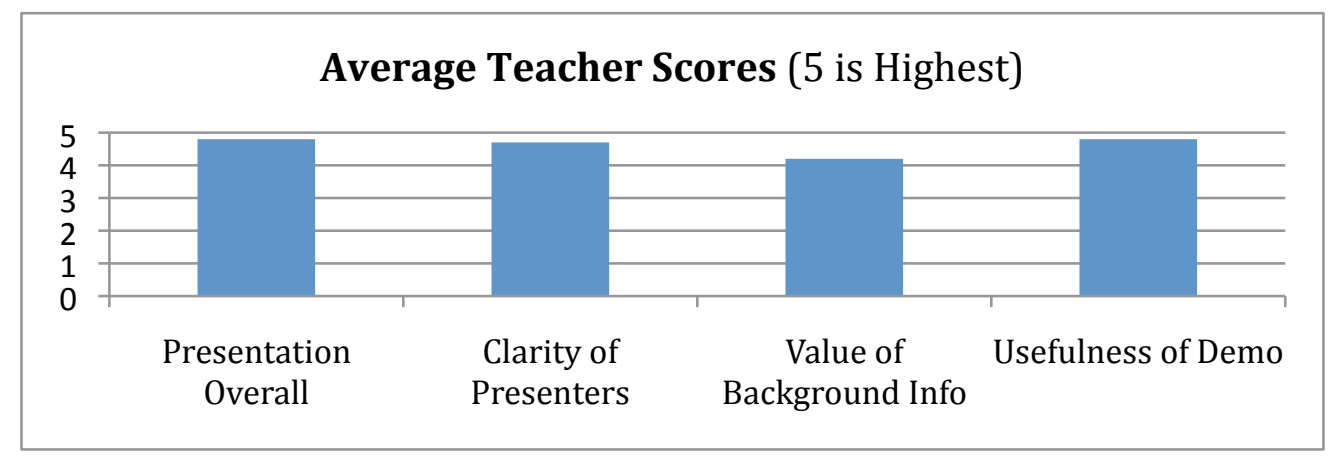

Figure 6. Assessment of the Optics Suitcase by 14 teachers in grades 5-8 in Milwaukee, WI. 


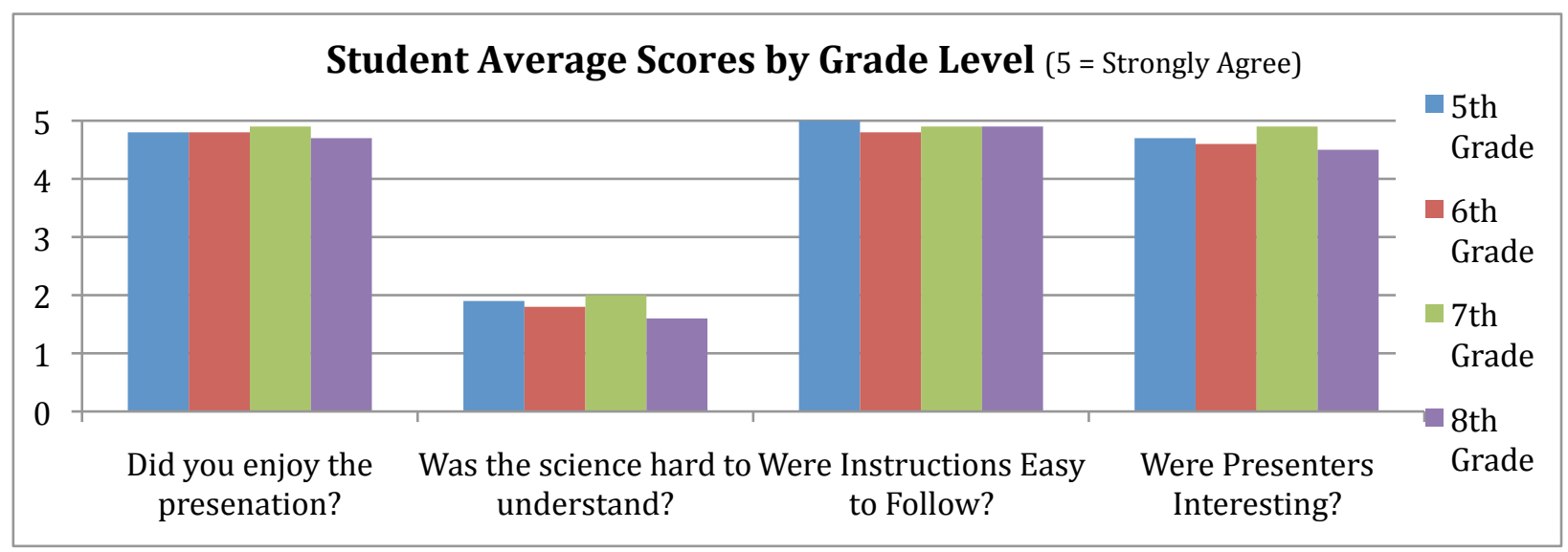

Figure 7. Assessment of the Optics Suitcase by 248 students in grades 5-8 in Milwaukee, WI.

The effectiveness of the presentation was scored by 14 teachers and 248 children on a scale from 1 to 5 , and the response was overwhelmingly positive. $98 \%$ of the children said they had liked the presentation, and $97 \%$ said they would share what they learned with a friend or family member. Further tools to assess the effectiveness of the program have recently been proposed in Serbia ${ }^{3}$.

\subsection{A global presence}

After the translation of the Optics Suitcase guide in 2011 into German, Spanish, Portuguese and Mandarin Chinese, the global presence of the Optics Suitcase keeps growing. So far, the Suitcase has been used in 34 states of the United States and in 54 countries, on all continents. Fig. 8 shows the map of the distribution of Suitcases as of July 2012.

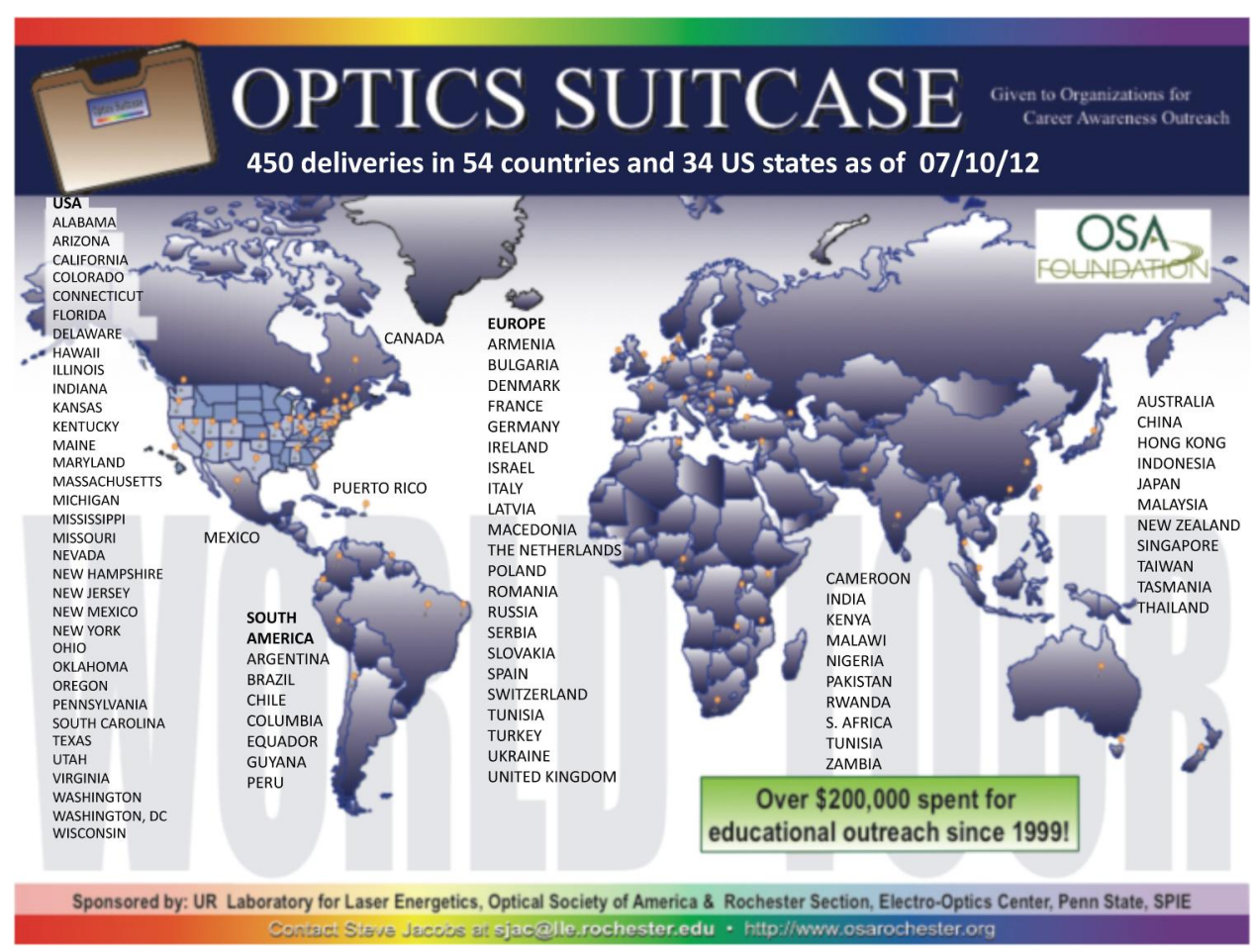

Figure 8. Distribution of the Optics Suitcase as of July 2012. 
In 2011, 75 Suitcases were assembled and distributed. Currently, ROSA is producing new Suitcases at full capacity (12 units/month). In 2011, applications for a free Optics Suitcase skyrocketed, and over 100 organizations had joined the waiting list. That same year, the OSA Foundation started handling shipping of the Suitcases directly, to help ROSA focus its efforts on Suitcase preparation. A set of criteria for evaluating requests was established, giving priority to organizations that had never received an Optics Suitcase, OSA student chapters/local sections, developing nations, and countries in which there is no Optics Suitcase. Priority is given to newly formed OSA and OSA/SPIE student chapters.

\section{OUTREACH EVENTS}

Countless presentations have been made with the Optics Suitcase. In additional to the many lessons given with the suitcases shipped around the world, several outreach events are organized directly by ROSA members, both locally and internationally. One of the more difficult but extremely rewarding presentations was given by Alexis Spilman Lanning in 2005, when she brought the Optics Suitcase to Malawi, in Africa, and presented the demonstrations to over 600 children ${ }^{4}$. The annual Family Night, taking place at The Institute of Optics at the University of Rochester since 2008, had a participation of over 150 people in 2011.

\section{CONCLUSION}

Since 1999, the Laboratory for Laser Energetics (LLE) has teamed with the Rochester Section of the Optical Society of America (OSA) to develop and administer the Optics Suitcase program. The principal goal of this program is to provide a demo lesson for college students, scientists and engineers to take into middle school classrooms. It is expected that, by enthusiastically discussing their careers, these visitors can motivate students to take math and science courses in high school, thereby "keeping the door open" for further training to enter technology fields after secondary school.

After thirteen years, the Optics Suitcase program is still going strong. Over 450 Suitcases have been distributed so far, and children all over the world have been introduced to the magic of optics.

\section{ACKNOWLEDGEMENT}

The Optics Suitcase is provided at no charge to institutions and groups promoting technology careers to young people. Support for our program has come from a variety of sources. The authors thank the ROSA for 13 years of financial and programmatic support. LLE (John Schoen) is acknowledged for the provision of space to assemble suitcases, shipping and receiving of materials (Paul Mittermeyer), procurement/tracking of supply orders (Rhonda Solomon, Jody Mayer), and billing (Barb Cronkite). Major funding and printing support has been provided by the OSA Foundation through the efforts of Grace Klonoski, Meredith Smith and Gale Mamatova. We acknowledge a major donation from James L. Fergason (1934-2008-the "father" of liquid crystal displays), and receipt of several grants from SPIE. Silica lenses have been donated by Edmund Optics (Marisa Edmund) and Optimax SI (Rick Plympton). Theme packets are assembled by the employees of the Progressive Workshop in Kittanning, PA (Roy Cigola and Candy Mangioni), and the per packet assembly fees are underwritten by the Electro-Optics Center of Penn State University (Wendy Gilpin and Laura Harvey). Through the efforts of these institutions and individuals, the cost to ROSA for the manufacture of a Suitcase has dropped by almost a factor of two from the inception of the program in 1999.

\section{REFERENCES}

[1] S. Jacobs, "Take-Home Demo Excites Young People About Careers in Technology," Optics and Photonics News, 16(11), 16-17 (2000).

[2] http://video.google.com/videoplay?docid=3938150847138169472

[3] O. M. Jakšic, "Teaching optics: preuniversity level," presented at the $19^{\text {th }}$ Telecommunications Forum (TELFOR 2011) on 22 November 2011, in the Sava Center, Belgrade (Serbia).

[4] A. Spilman Lanning, "Unpacking my "Optics Suitcase" in Africa," Optics and Photonics News, 16(11), 14-15 (2005). 